\title{
The Board Marks Its 30th Anniversary
}

1999 marks the 30th anniversary of the American Board of Family Practice. When we look back 30 years to its founding, we wonder who would have believed that a young physician from the University of Kentucky, who had conceived of the concept of certifying and recertifying family physicians, could assemble a board of directors of his peers and make that concept work. In retrospect, the efforts to achieve success must have been daunting, and it is an understatement to say that the concept of certification and recertification was met with some resistance within the medical community.

Today the concept upon which the ABFP was established has turned out to be visionary. ABFP founder, Nicholas J. Pisacano, MD, (1924-1990) and his first board of directors believed strongly that certifying family physicians would ensure the public of a high-quality physician. Through the strength of this pioneering group's commitment, certification and recertification are now the accepted standards and bring an undeniable credibility to the specialty. At more than 54,000 certified diplomates, family practice is the second largest medical specialty in the United States.

The success of the ABFP in maintaining its high standards for both its policy and its examinations can be traced directly to its outstanding staff and active Board of Directors. Each Board member serves on a number of committees during his or her tenure. Robert F. Avant, MD, Executive Director of the ABFP states, "Our Board members are essential to our success. Each is selected for his or her ability to bring unique perspectives and experiences to help us examine our policies and the important issues that relate to family physicians today."

The ABFP Board of Directors consists of 15 members selected by the Board. There are 10 family physicians - 5 nominated through the American Academy of Family Physicians (AAFP) and 5 nominated by other organizations or by the Board. In addition, there are representatives from five other specialties including internal medicine, surgery, pediatrics, obstetricsgynecology, and psychiatry-neurology. Each Board member serves for 5 years. All members of the Board of Directors are physicians and must be certified.

\section{New Officers Elected}

Four new officers were elected to the Board in April. Each is experienced and has participated on a number of the Board's committees. We have asked each to reflect, in their own words, what their service on the Board has meant to them.

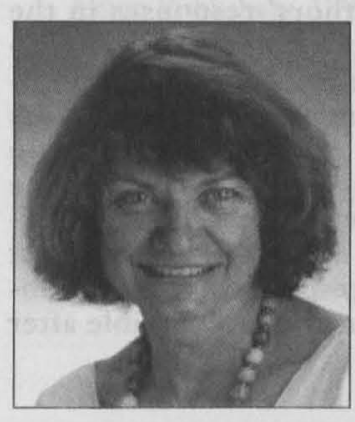

Cynda Johnson, MD, MBA, President, is currently Interim Chair, Department of Family Practice, University of Kansas School of Medicine. Dr. Johnson believes that the time she has served on the Board and its committees has been important because the ABFP is a Board "where you can make a difference." She states, "It is undoubtedly the best professional experience that I have had. It has been a wonderful opportunity to work with an ever-changing group of people who are bright, intelligent, and visionary. Each individual considers it his or her charge to ensure that the quality of health care for patients and the assessment of the medical profession will continue to meet the highest standards."

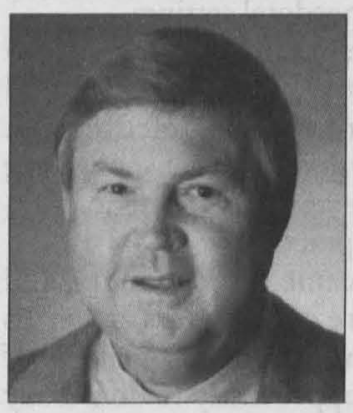

J. Lewis Sigmon, Jr, MD, Vice President, is currently Director of Carolinas Medical Center Family Practice Rural Residency Program in Monroe, North Carolina. Dr. Sigmon states, "The time that I have served on the Board has been both personally and professionally gratifying." He continues, "It gave me the opportunity to serve and work shoulder-to-shoulder with the individuals whom I consider the giants of the specialty of family practice. I also enjoyed having the opportunity to be exposed to the perspectives of other specialists on the Board regarding tough issues and policies that it faces." Dr. Sigmon also states, "I am honored to have been given this opportunity to help ensure the continued quality and credibility of family practice in the United States."

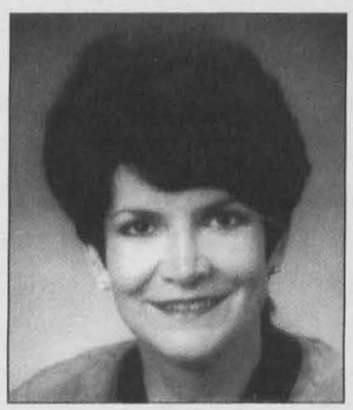

Deborah I. Allen, MD, Treasurer, is currently the Otis Bowen Professor at Indiana University School of Medicine. During her time on the Board, she has been "totally impressed by the unselfishness shown by the individuals who make up the Board. They spend a 
great amount of time working and thinking about the quality of family practice in this country." Dr. Allen, who has extensive experience at all levels of testing, comments, "Only those who are extremely dedicated to their specialty could improve upon what I already consider a great testing procedure. What makes my service to the Board even more gratifying is that we strive to assess better the quality of family physicians and their practice while continuing to enhance the credibility of the specialty."

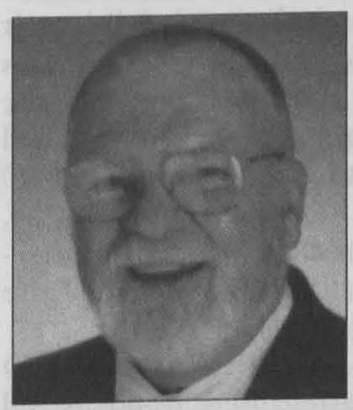

R. Jerry Mann, MD, Member-at-Large to the Executive Committee, is currently Assistant Professor, Associate Residency Director, Department of Family Medicine, University of Kansas School of Medicine. Dr. Mann believes that "my time and service to the Board is a constant reminder of my personal obligation to educate properly and fully train our future family physicians." He continues, "I believe it is important to give something back to the specialty that has given me so much." Most importantly, "I believe it is my obligation to the citizens of our country to certify family physicians properly, thereby safeguarding the specialty and ensuring our Diplomates that their certification is 100 percent credible."

\section{New Board Members Selected}

Also selected in April were three new Board members. Each brings a variety of experiences from both private practice and academia.

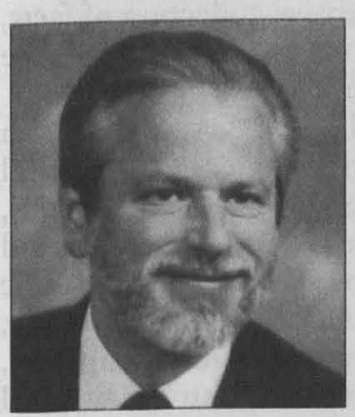

Ronald E. Christensen, $\mathrm{MD}$, brings a unique viewpoint from both his private family practice and service experience with other medical organizations. $\mathrm{He}$ states, "I am deeply honored to be appointed to the Board. Since 1977, I have been an in-the-trenches family physician in both rural and urban Alaska and have served our specialty on a number of committees, including 8 years on the AAFP Commission on Education." Dr. Christensen realizes that the Board's challenges are unique, and he hopes that his insight and experience will be helpful to serve the ABFP and its diplomates.

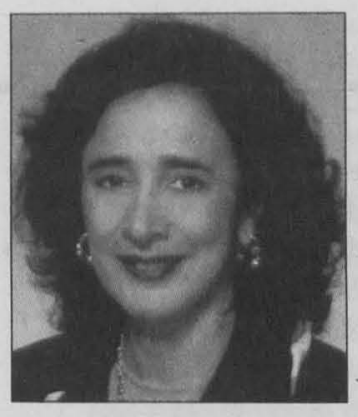

Valerie M. Parisi, MD, MPH, is currently Robert A. Ross Professor and Chair of Obstetrics and Gynecology at the University of North Carolina, Chapel Hill, specializing in maternal fetal medicine. Dr. Parisi brings experience in both clinical practice and academic administration and currently serves as a director on the American Board of Obstetrics and Gynecology. Dr. Parisi states, "I feel very fortunate to have the opportunity to serve on the Board and share my experience in the specialty. I hope this will add new insights to the everyday issues of family practice and be mutually beneficial to all practitioners. I look forward to working with this outstanding group of individuals."

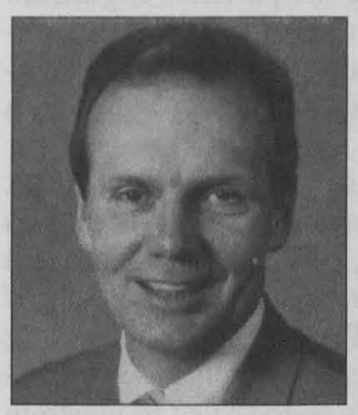

Joseph E. Scherger, MD, MPH, is currently Professor and Chair, Department of Family Medicine, University of California, Irvine. He states, "I am humbled by the opportunity to continue to spread and uphold the heritage of family practice that has been carried on for generations before me." He continues, "I have fond memories of meeting Dr. Pisacano when I was in residency. I find his vision of establishing the certification and recertification process to be remarkable." It is Dr. Scherger's intention to use his experience from private practice and academia to assist the Board in improving the quality of measurement as pertains to family physicians today.

As the Board enters the 21st century, it will continue to strive to make improvements in the assessment of family physicians, and it will continue to depend on the dedication and commitment of its members to safeguard the specialty and ensure that the diplomates' certification is credible to the public. To quote Dr. Pisacano from a 1980 interview: "I'll tell you one thing we've learned: we're never perfect. The minute that we think we're quite good is when we're going to kick ourselves in the rear end-and I mean that sincerely. We're proud of what we've done, but we are not the least bit complacent. The desire for continued self-improvement is a hallmark of the ABFP." 